\title{
ПРИМЕНЕНИЕ «ВОСПРОИЗВОДСТВЕННОГО ПОДХОДА》 В ЦЕЛЯХ РЕШЕНИЯ ЖИЛИЩНОЙ ПРОБЛЕМЫ В СТРАНЕ
}

\author{
Г. В. Хомкалов ${ }^{1}$, И. Г. Торгашина ${ }^{1}$, К. В. Демьянов ${ }^{2}$ \\ 'Байкальский государственный университет, г. Иркутск, Российская Федерация \\ 2000 «Ростосстрах", г. Якутск, Российская Федерация
}

\author{
Информация о статье \\ Дата поступления \\ 20 ноября 2017 г. \\ Дата принятия к печати \\ 28 февраля 2018 г. \\ Дата онлайн-размещения \\ 30 марта 2018 г.

\section{Ключевые слова} \\ Жилищная проблема; \\ обеспеченность жильем; \\ воспроизводство жилищного \\ фонда; улучшение жилищных \\ условий; дифференцирование \\ функции; эластичность \\ функции; метод наименьших \\ квадратов
}

\begin{abstract}
Аннотация
Цель данного исследования состоит в разработке модели «воспроизводственного подхода», направленной на совершенствование механизмов решения жилищной проблемы. Авторами проведен анализ показателей, отражающих динамику жилищного фонда, с применением методов математической статистики. В модели учтено влияние объемов ввода и выбытия жилых площадей из эксплуатации, объемов капитального ремонта, а также демографической ситуации. Частные производные от функции, характеризующей процесс воспроизводства жилищного фонда, послужили основой модели «воспроизводственного подхода». Модель рассмотрена на примере Иркутской области. Ее внедрение на макроуровне позволит регулировать динамику обеспеченности населения жилой площадью путем сбалансированного изменения объемов воспроизводимого жилья. В статье обоснована эфрфективность комплексного использования основных форм воспроизводства жилья на основе модели «воспроизводственного подхода».
\end{abstract}

\section{APPLICATION OF THE «REPRODUCTIVE APPROACH» FOR THE PURPOSE OF SOLVING THE HOUSING PROBLEM IN RUSSIA}

\author{
Gennady V. Khomkalov'1, Irina G. Torgashina', Konstantin V. Demyanov² \\ ${ }^{1}$ Baikal State University, Irkutsk, the Russian Federation \\ ${ }^{2}$ JSC «Rosgosstrakh», Yakutsk, the Russian Federation
}

Article info

Received

November 20, 2017

Accepted

February 28, 2018

Available online

March 30, 2018

\section{Keywords}

Housing problem; housing provision; housing stock reproduction; housing improvement; function differentiation; elasticity of function; method of least squares

\begin{abstract}
The present study subject is to develop a model of the «reproductive approach» for the purpose of improving mechanisms of the housing problem solution. The authors perform an analysis of indicators reflecting housing stock dynamics with an application of mathematical statistics methods. The model takes an account of such factors as an influence of the amount of living space taken into and out of use, scope of total building renovation as well as a demographic situation. Partial derivatives of the function outlining the process of housing stock reproduction make up the basis of the "reproductive approach» model. The application of the model is illustrated by an example of Irkutsk Oblast. Introduction of the model at the macro-level will allow to regulate the housing provision dynamics by means of a balanced alteration in the scope of the reproduced housing. The article substantiates efficiency of comprehensive use of the main forms of the housing reproduction on the basis of the "reproductive approach».
\end{abstract}

Одним из приоритетных направлений государственной жилищной политики до 2030 г. является решение жилищной проблемы в стране путем обеспечения граждан комфортным и доступным жильем за счет строительства новых жилых домов, а также снижения изношенности существующего жилищного фронда. В дополнение к работам по уменьшению износа жилья с учетом практики зарубежных стран рекомендуется внедре- 
ние современных технологий строительства с последующим благоустройством придомовой территории, позволяющее улучшить существующую архитектуру города, доводя его облик до уровня мегаполисов развитых стран [1; 2]. Непосредственное увеличение темпов жилищного строительства в целом по стране, включая жилье экономкласса, даст возможность сбалансировать формируемый спрос на жилую недвижимость и существующее предложение на рынке жилья в регионах. Достижение условий равновесия на рынке жилой недвижимости в рамках существующей длительности инвестиционно-строительного цикла в процессе воспроизводства жилья [3; 4] сделает возможным увеличение количества жилой площади, приходящейся на душу населения, и улучшит условия проживания в стране.

Анализ состояния рынка недвижимости свидетельствует о неудовлетворительных показателях, полученных в ходе реализации мероприятий жилищной политики, проводимой государством. Установленный в процессе исследования темп прироста жилищного фонда' на дату оценки (начало 2016 г.) достиг значения 47,7 \%, что превышает значение базового периода (1990г.) в 1,5 раза. Увеличение размеров жилищного фонда объясняется стремлением государства в рамках реализации мер жилищной политики стимулировать строительство новых жилых домов различной социальной направленности. По данным Минстроя, в 2017 г. в России будет введено 75-76 млн м² жилой площади, что меньше, чем в рекордном 2016 году, когда было построено более 80 млн м² жилья. Объясняется это нестабильной макроэкономической ситуацией, в условиях которой строительство жилья стало осуществлять меньшее число застройщиков. Планируя ежегодное увеличение темпов ввода жилья, государство стремится достичь условий воспроизводства жилищного фонда в расширенном масштабе. Применение данной формы воспроизводства обеспечивает прирост вводимых в эксплуатацию жилых площадей, распределяемых в дальнейшем в соответствии с рыночными механизмами и фредеральными программами, направленными на повышение доступности жилья для домохозяйств, нуждающихся в улучшении условий проживания. На фоне тенденций по улучшению качества жилищных условий наблюдается существенное увеличение объема

Российский статистический ежегодник. 2016 : стат. сб. / Росстат. М., 2016. 725 с. ветхого и аварийного фонда², темп прироста которого на дату оценки составил порядка $92 \%$, что в 1,9 раза превышает показатели базового периода. По данным Счетной палаты, объем ветхого и авариного фонда с учетом зданий, признанных таковыми после 2012 г., составит порядка 10,5 млн м², которые ввиду нецелесообразности восстановления необходимо полностью расселить, что требует значительных расходов со стороны федерального центра. Увеличение объемов капитального ремонта до 40-45 тыс. домов в год с целью изменить ситуацию с ветхим и аварийным жильем не дает удовлетворительных результатов, что приводит к необходимости участия федерального центра в замещении изношенного фонда. Установленное превышение темпов ветшания и аварийности жилищного фонда над приростом совокупного количества жилой площади указывает на возникающий дефицит жилой площади, рост которого повышает степень актуальности жилищной проблемы. От катастрофической ситуации в жилищной сфере, обусловленной нехваткой жилья, спасает демографическое положение в стране, но при этом существенно не снижает ее остроты. По данным исследования, в период с 1991 г. в стране наблюдается сокращение численности населения на 1,2 \%, или в 1,012 раза. Низкие демографические показатели косвенным путем компенсировали нехватку жилой площади в регионах, однако, принимая во внимание оптимистический сценарий развития ${ }^{3}$ в период с 2017 по 2050 г. прогнозный темп прироста населения должен достигнуть $11,5 \%$, или в 1,1 раза увеличить численность населения страны. Сопоставляя темпы прироста жилищного фонда, ожидаемое увеличение населения в стране с динамикой показателей по ветхому и аварийному фонду, стоит отметить необходимость развития и доработки существующих подходов, направленных на улучшение жилищных условий в стране. Подтверждает сделанные выводы динамика показателя, характеризующего размер жилой площади, приходящейся на среднестатистического жителя. На дату оценки величина показателя выросла в 1,5 раза и составила $24,4 \mathrm{M}^{2}$ на человека 4 . В сравнении с развитыми европейскими странами, где данная величина колеблется от 40 до $60 \mathrm{M}^{2}$, а в США составляет порядка $70 \mathrm{M}^{2}$, следует вывод о необходимости улучшения условий проживания в регионах России

\footnotetext{
${ }^{2}$ Российский статистический ежегодник. 2016.

3 Там же.

${ }^{4}$ Там же.
} 
до уровня развитых стран, где данные нормы для человека считаются оптимальными и позитивно влияющими на развитие бизнеса и благосостояния нации $[5 ; 6]$. Сочетание этих факторов в условиях рыночных цен на жилье указывает на необходимость проведения оценки доступности приобретаемого жилья, предлагаемого государством в качестве основного инструмента, позволяющего обеспечить население жилой площадью. Величина показателя определяется количеством лет, необходимых для приобретения жилья исходя из дохода среднестатистического домохозяйства, состоящего из трех человек и намеревающегося купить жилое помещение в собственность для улучшения условий про-

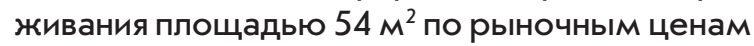
за счет собственных и заемных средств. При 100-процентном использовании дохода на оплату расходов, связанных с приобретением жилья, платежи составят не менее 8 лет. Длительность платежей с использованием трети дохода на покупку жилья составит не менее 23 лет. Вариант, предусматривающий использование половины дохода, позволит рассчитаться за приобретаемое жилье не менее чем за 15 лет. В качестве пояснения стоит отметить, что расчет проводился исходя из средней стоимости $1 \mathrm{M}^{2}$ жилья в целом по стране, при этом значительного расхождения цен на первичном и вторичном рынке установлено не было, таким образом, представленные результаты оценки характеризуют ситуацию на рынке жилья в целом. Результаты анализа указывают на существенные ограничения в бюджете среднестатистического домохозяйства, вызванные расходами на приобретение жилья. Сделанный вывод свидетельствует о низкой доступности приобретаемого жилья, что в условиях прогрессирующего износа жилищного фонда ограничивает возможности семьи улучшить условия проживания. Данные фракторы с учетом тенденций в жилищной политике и прогноза ситуации в жилищной сорере на 2052 г. позволяют отметить, что эффрективного решения жилищного вопроса ожидать не приходится. Согласно исследованиям, проведенным с использованием трендовых моделей, на дату прогноза объем вводимого в строй жилья будет отставать от динамики показателей ветхого и аварийного фонда в 1,8 раза, с учетом того что покупательная способность населения будет расти и существующие возможности жилищного строительства будут максимально реализованы. С учетом темпов строительства, не превышающих выбытие ветхих и авариных домов, ожи- даемое значение обеспеченности населения жилой площадью к 2052 г. сможет возрасти не более чем на $6 \mathrm{M}^{2}$ и составить порядка 30,4 м $^{2}$ на человека, что ниже норм обеспеченности жильем в развитых европейских странах. Положение дел, характеризуемое превышением динамики выбытия жилищного фонда над приростом вводимого в строй жилья, в условиях увеличения населения на $13 \%$ не позволит удовлетворить спрос на жилую недвижимость существующим предложением, что ведет к дефициту жилой площади, следовательно, и к повышению актуальности проблемы с жильем.

Вышеприведенная аналитика свидетельствует о том, что жилищная проблема далека от решения, в связи с чем необходимо уделить внимание развитию механизмов планирования жилищного строительства совместно с организацией работ по снижению изношенности жилищного фонда. Реализация данного направления требует создания комплексного подхода, позволяющего определять динамику обеспеченности населения жильем в процессе регулирования объемов вводимого жилья совместно с работами по уменьшению износа жилищного фонда. Предлагаемый подход позволит качественно улучшить условия проживания не только в отдельно взятом регионе, но и в целом по стране, фрормируя предпосылки для достижения обеспеченности населения жильем на уровне зарубежных стран, что будет стимулировать развитие бизнеса и рост благосостояния нации.

В настоящее время для удовлетворения спроса на жилье различной степени комфортности, повышения доступности приобретаемого жилья, замещения ветхого и аварийного фонда, достижения масштабов расширенного воспроизводства жилищного фонда используется строительство новых жилых домов и проведение работ по снижению изношенности жилых зданий (капитальный, текущий ремонт, реконструкция и модернизация зданий). Значительное внимание предлагается уделить увеличению доли массовых проектов в структуре предложения на рынке жилья, не уступающего по технологическим решениям зарубежным аналогам [7]. Совместно с этим планируется возведение арендного жилья, способного на условиях найма обеспечить население жилой площадью, что дополнительно позволит мотивировать экономически активную часть населения страны для переезда к новым рабочим местам. В особый вид работ по снижению износа выделена реновация жилищного фонда, состоящая в замещении 
зданий, имеющих существенный фризический и экономический износ, новыми жилыми зданиями. Поэтапное обеспечение строительного производства материалами, не уступающими по качеству зарубежным аналогам [8], будет способствовать реализация стратегии развития строительных материалов и индустриального домостроения, направленной на повышение качества возводимых объектов. Имущественные отношения на вводимое в строй жилье в условиях рыночных отношений возникают в результате приобретения в собственность жилого помещения за счет собственных и заемных средств (ипотека) или инвестирования их в долевое строительство жилого дома либо на условиях найма жилья. Стоит отметить, что данные схемы выступают в качестве основных драйверов жилищной политики, проводимой государством для улучшения жилищных условий в стране. Однако, как показывает практика, покупка жилья с использованием собственных и заемных средств имеет ряд ограничений. Функционирование экономики в условиях низких цен на нефть, наличия внешних санкций и ограничений, снижения ВВП, высокой инфляции и волатильности курса рубля не позволяет Банку России снизить ключевую ставку, что существенно ухудшает условия кредитования в стране. В результате государство вынуждено применять меры фринансовой поддержки для ипотечных заемщиков и стабилизации рынка ипотечного кредитования. Неблагоприятная макроэкономическая ситуация привела к падению реальных доходов населения, вызвавшему снижение потребительского спроса. Потребители, выступающие в роли инвесторов, не отмечают стабильности в экономической ситуации, в результате происходит увеличение накоплений, уменьшающее потребительскую активность и увеличивающее риск снижения спроса на жилье. В то же время отмеченный рост сбережений со стороны населения не дает возможности нуждающимся домохозяйствам накопить первоначальный взнос на получение ипотечного кредита, составляющий 15-20\% от стоимости приобретаемого жилья. Это указывает на низкий уровень доходов семьи и его нестабильность, что снижает доступность ипотечных займов в условиях применения льготной системы кредитования. Возведение жилья за счет долевого фринансирования строительных работ, осуществляемое в рамках региональных программ, предусматривающих компенсацию процентов по кредитам, полученным в российских учреждениях, позволяет расширить число потенциальных заемщиков, нуждающихся в жилье. Дополнительно к этому гражданам, объединившимся в жилищно-строительные кооперативы для некоммерческого строительства жилья, правительство планирует на безвозмездной основе выделять земельные участки, в том числе находящиеся в федеральной собственности, что существенно сокращает себестоимость строительства. Однако существующий в России механизм долевого участия в строительстве жилья имеет ряд существенных недостатков, в результате чего возникает риск не достроить объект, а инвесторы (физические лица дольщики) могут остаться без жилого помещения и понести убытки от инвестиционной деятельности. Решение проблемы обманутых дольщиков путем совершенствования правовой и экономической базы, направленной на обеспечение сохранности средств, включая внедрение эскроу-счетов, ужесточение ответственности за мошенничество, повышение качества возводимых объектов, создание компенсационного фонда и т. д., на данный момент недостаточно проработано. Таким образом, приведенные предпосылки позволяют сделать вывод, что используемые в настоящее время инструменты в решении жилищной проблемы не являются универсальными и не позволяют достичь требуемого количества жилой площади.

В ходе непрерывного совершенствования инструментов решения жилищной проблемы предложен механизм реновации жилых зданий, направленный на уменьшение изношенности жилищного фонда. Предлагаемая мера разработана в качестве альтернативы строительным работам, проводимым с целью снижения общего износа жилищного фонда, фринансирование которых осложняется недостатком средств вследствие недостаточной проработанности механизма их формирования. Несмотря на существующие достоинства разработанной программы и активное ее продвижение в Москве и Санкт-Петербурге, замещение жилья, экономический износ которого превышает физический, имеет ряд дискуссионных моментов. В первую очередь детально не проработана типология возводимых объектов. Указанные недочеты приведут к строительству домов, идентичных сносимым объектам, только имеющим большее число этажей. Во-вторых, подробно не представлен анализ альтернативных вариантов, доказывающий экономический эфффект от проводимой реновации. Это важно для тех регионов, где дома, соответствующие 
условиям реновации, составляют более $50 \%$ всего жилищного фонда, в отличие от Москвы и Санкт-Петербурга, где их не более 30 \% от общего количества жилья. Поэтому для регионов наиболее рациональны предложения по совершенствованию механизмов финансирования работ в части снижения изношенности зданий, что позволяет сократить объем ветхого и аварийного фонда, требующего расселения жильцов. Дополнительно стоит отметить недостатки в законодательной базе, не обеспечивающие защиту интересов собственников сносимых домов от мошеннических действий в ходе реализации программы реновации жилья. Таким образом, в целях качественного улучшения жилищных условий в стране, по нашему мнению, необходимо использовать сочетание основных форм воспроизводства жилищного фонда, дающее возможность исходя из требуемой обеспеченности жилой площадью регулировать объемы строительства и ремонтных работ, включающих модернизацию и реконструкцию объектов. Предложенная авторами идея, составившая основу «воспроизводственного подхода», позволяет удовлетворять спрос на жилую недвижимость, тем самым уменьшая существующий дефицит жилой площади в целом по стране. Поэтому для разработки предлагаемого авторами подхода необходимо детально исследовать механизм планирования объемов строительства и ремонта жилья, обладающего в соответствии с приведенной выше аналитикой низкой производственной эфффективностью.

Планирование объемов жилищного строительства проводится непосредственно в рамках региональных программ жилищной политики с учетом потребности субъектов РФ в жилых помещениях для различных категорий граждан и существующего платежеспособного спроса на жилые помещения. Ожидаемые объемы жилищного строительства рассчитываются исходя из информации о площадях земельных участков, предоставленных для комплексного и индивидуального возведения домов, в соответствии с которой выдаются разрешения на строительство жилых зданий, определяющие общее количество вводимого жилья, с учетом сроков строительства и степени готовности объектов. Информация о площади земельных участков консолидируется либо из системы административного учета, содержащей данные об участках, предоставляемых без проведения торгов, либо из протоколов, когда земельные участки предоставляются посредством проведения торгов. Число разрешений на возведение жилья, выданных строительным организациям, устанавливается путем их общего подсчета и с учетом степени готовности объекта к эксплуатации дает возможность прогнозирования объемов жилищного строительства. Необходимый размер финансирования предстоящего строительства определяется произведением запланированных объемов на среднюю стоимость квадратного метра вводимого в эксплуатацию жилья. Равномерное введение запланированных объемов производится за счет использования норм задела по общей площади жилых домов, установленных в зависимости от продолжительности строительства зданий, и является обязательным для исполнения.

В части планирования работ по капитальному ремонту либо реконструкции или модернизации жилья в целях уменьшения их общего износа количество ремонтируемых домов определяется путем обобщения информации, поступающей от собственников многоквартирных домов, принявших на общем собрании решение о проведении в доме ремонтных работ. Решение о проведении работ собственники принимают на основании информации о техническом состоянии жилого дома, полученной в ходе его обследования. В ситуации, когда собственниками не принято решение о необходимости проведения работ по уменьшению износа здания, а состояние жилого дома указывает на это, власти субъекта Рф в рамках реализации мероприятий региональной программы капитального ремонта включают многоквартирный дом в данную программу и проводят ремонтные работы за счет средств регионального оператора. Стоит отметить, что затраты на последующий капитальный ремонт, в том числе и для вновь введенных в эксплуатацию домов, будут напрямую зависеть от качества строительных работ [9; 10], высокий уровень которых достигается путем использования современных методов управления строительным производством и присутствием в строительной организации квалифицированного персонала [7]. Дополнительно к этому правительством разработан ряд мер, направленных на совершенствование системы формирования фондов капитального ремонта и средств, за счет которых планируется фринансирование ремонтных работ, но при этом совсем не уделяется внимания созданию комплексного подхода, позволяющего консолидировать существу- 
ющие формы воспроизводства жилья для совместного их использования. Это является одной из основных причин низких показателей в ходе реализации региональных программ капитального ремонта.

Как видно из описанных выше подходов, используемых в решении жилищной проблемы, их основным недостатком является отсутствие количественной связи между показателями, характеризующими изменение вводимого в строй жилья и его выбытие по причине изношенности, с показателем обеспеченности населения жильем. Из этого следует, что логика, заложенная в данных подходах, заключается в раздельном использовании форм воспроизводства жилья, включая подсчет их количественных показателей, от которых напрямую зависит изменение совокупного размера жилищного фронда, связанного с притоком или выбытием жилья, что не дает возможности комплексного определения требуемых объемов воспроизводства для конкретной ситуации. Сделанное заключение выступает в качестве главной посылки, позволяющей констатировать необходимость доработки существующих подходов к планированию объемов воспроизводимого жилья.

В связи с этим для устранения существующих недостатков указанных выше подходов предлагается создать модель в рамках «воспроизводственного подхода», позволяющую оценивать обеспеченность насе- ления жилой площадью в зависимости от изменения ее основных компонент - объемов вводимого в строй жилья и количества отремонтированных либо модернизированных (реконструированных) жилых домов. Достижение поставленной цели указывает на необходимость решения задачи по аналитическому описанию ситуации с жильем в регионе и получению математического выражения (путем взятия частных производных от полученной функции по каждому из аргументов), отражающего динамику показателя обеспеченности населения жильем в зависимости от изменения аргументов, характеризующих приток или выбытие жилищного фонда.

В силу поставленных в исследовании задач на примере Иркутской области по имеющейся статистической информации предлагается исследовать ряд зависимостей, не связанных между собой, но влияющих на динамику обеспеченности населения жильем. Первая зависимость представляет сопоставление количества жилой площади, приходящейся на одного жителя региона, $\operatorname{Pr}$ с его общей площадью $S$. Информация, необходимая для исследования зависимости $\operatorname{Pr}=f(S)$, представлена в табл. 1.

Далее для наглядности статистические данные, описывающие зависимость $\operatorname{Pr}=f(S)$, переносятся на координатную плоскость, графическое положение точек представлено на рис. 1.

Таблица 1

Информация о количестве жилой площади, приходящейся на жителя Иркутской области, и общей площади жилых помещений в регионе *

\begin{tabular}{|c|c|c|c|c|c|c|c|c|c|}
\hline Показатель & 2000 & 2005 & 2009 & 2010 & 2011 & 2012 & 2013 & 2014 & 2015 \\
\hline $\begin{array}{l}\text { Обеспеченность } \\
\text { жилой площадью жителя } \\
\text { Приангарья }(P r), \text { м }^{2} \\
\text { на жителя }\end{array}$ & 18,8 & 19,7 & 20,5 & 21,4 & 21,7 & 22,1 & 22,3 & 22,7 & 23,1 \\
\hline $\begin{array}{l}\text { Жилищный фонд (S), } \\
\text { всего, тыс. м² }\end{array}$ & 49406,3 & 49742,6 & 51372,1 & 51870,5 & 52729,3 & 53476,9 & 53901,5 & 54899,5 & 55717,1 \\
\hline
\end{tabular}

* Составлена по данным: Российский статистический ежегодник. 2016 : стат. сб. / Росстат. М., 2016.725 с.

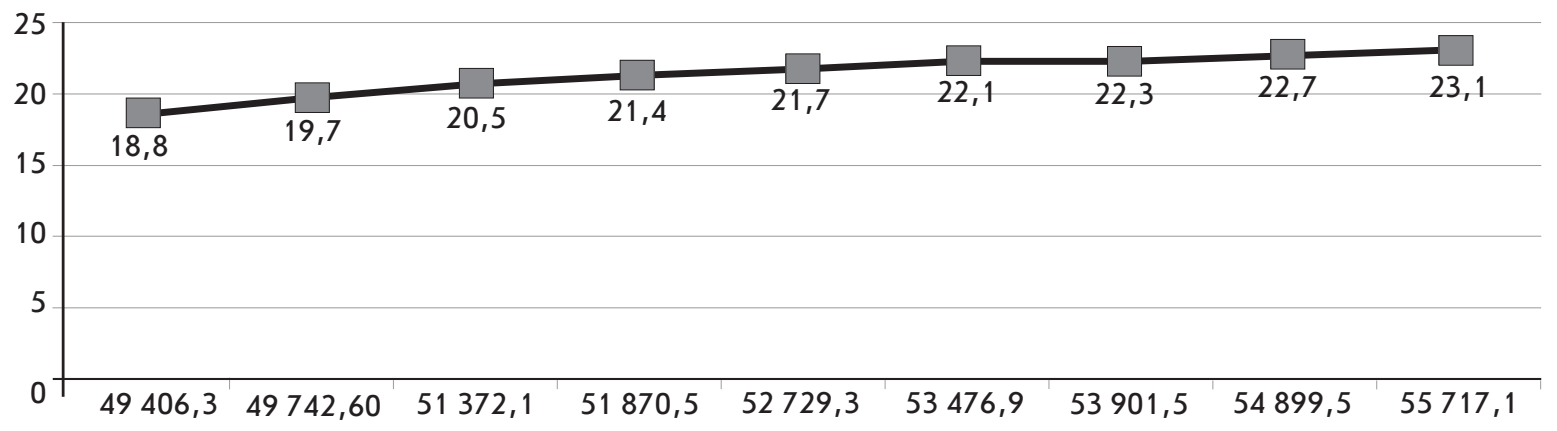

Рис. 1. Функция $\operatorname{Pr}=f(S)$ 
Следующая зависимость представлена сопоставлением показателей обеспеченности населения жилой площадью $\operatorname{Pr}$ и вводом в эксплуатацию построенного жилья En в данной местности. Статистическая информация о значениях показателей содержится в табл. 2.

Графическое положение точек, описывающих зависимость $P r=f(E n)$, представлено на рис. 2.

Завершает ряд исследуемых зависимостей сопоставление значений показателей обеспеченности среднестатистического жителя региона жилой площадью $\operatorname{Pr}$ с объемом ветхого и аварийного фонда по области Wo.
Количественные значения сопоставляемых показателей представлены в табл. 3 .

Графическое положение точек зависимости $\operatorname{Pr}=f(W o)$ показано на рис. 3.

Расположение точек на координатной плоскости дает возможность констатировать наличие линейной зависимости между исследуемыми показателями. Установив линейную зависимость между изучаемыми показателями, необходимо перейти к аналитическому описанию рассмотренных зависимостей, для чего предлагается использовать метод наименьших квадратов, позволяющий определить коэфффициенты $a$ и $b$ линейного

Таблица 2

Информация о количестве жилой площади, приходящейся на жителя Иркутской области, и вводе в действие жилых домов в регионе

\begin{tabular}{|l|r|r|r|r|r|r|r|r|r|}
\hline \multicolumn{1}{|c|}{ Показатель } & 2000 & 2005 & 2009 & 2010 & 2011 & 2012 & 2013 & 2014 & 2015 \\
\hline $\begin{array}{l}\text { Обеспеченность жилой площадью } \\
\text { жителя Приангарья (Pr), м² на жителя }\end{array}$ & 18,8 & 19,7 & 20,5 & 21,4 & 21,7 & 22,1 & 22,3 & 22,7 & 23,1 \\
\hline $\begin{array}{l}\text { Ввод в действие жилых домов в регионе } \\
\text { (Еn), тыс. м² }\end{array}$ & 185,8 & 302,5 & 602,2 & 628,1 & 755,2 & 871,1 & 973,3 & 835,6 & 922,6 \\
\hline
\end{tabular}

* Составлена по данным: Российский статистический ежегодник. 2016.

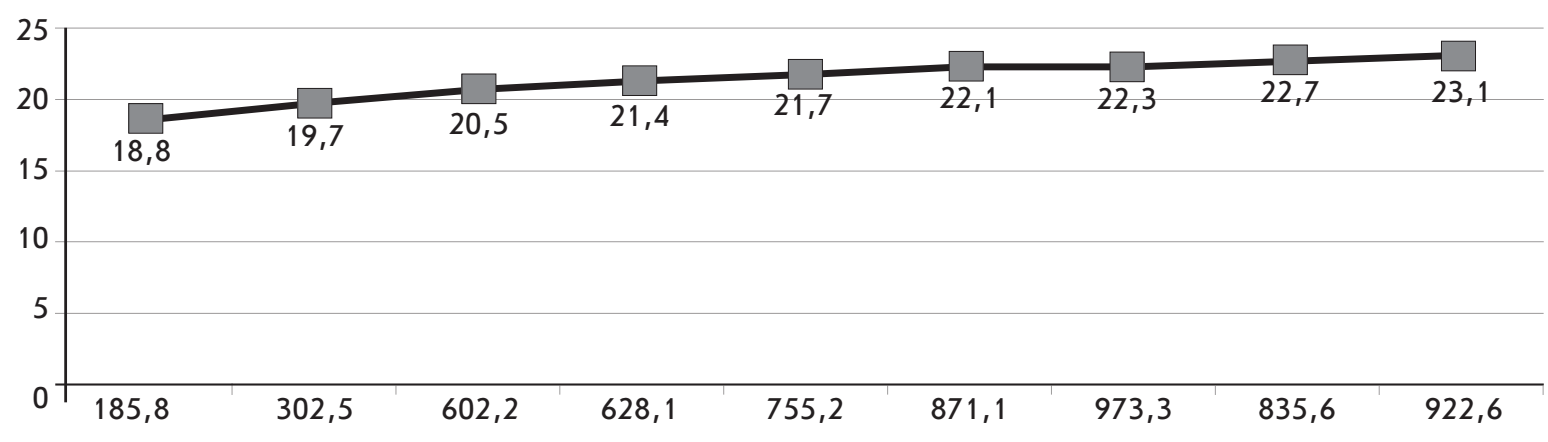

Рис. 2. Функция $\operatorname{Pr}=f(E n)$

Таблица 3

Информация о количестве жилой площади, приходящейся на жителя Иркутской области, и объемы ветхого и аварийного фонда в регионе *

\begin{tabular}{|c|c|c|c|c|c|c|c|c|c|}
\hline Показатель & 2000 & 2005 & 2009 & 2010 & 2011 & 2012 & 2013 & 2014 & 2015 \\
\hline $\begin{array}{l}\text { Обеспеченность жилой площа- } \\
\text { дью жителя Приангарья (Pr), } \text { м }^{2} \\
\text { на жителя }\end{array}$ & 18,8 & 19,7 & 20,5 & 21,4 & 21,7 & 22,1 & 22,3 & 22,7 & 23,1 \\
\hline $\begin{array}{l}\text { Ветхий и аварийный фонд (Wo), } \\
\text { тыс. } \text { м }^{2}\end{array}$ & 1520,1 & 3290,7 & 4186,5 & 4439,6 & 4589,3 & 4528,6 & 4189,8 & 4247,2 & 3228,3 \\
\hline
\end{tabular}

* Составлена по данным: Российский статистический ежегодник. 2016.

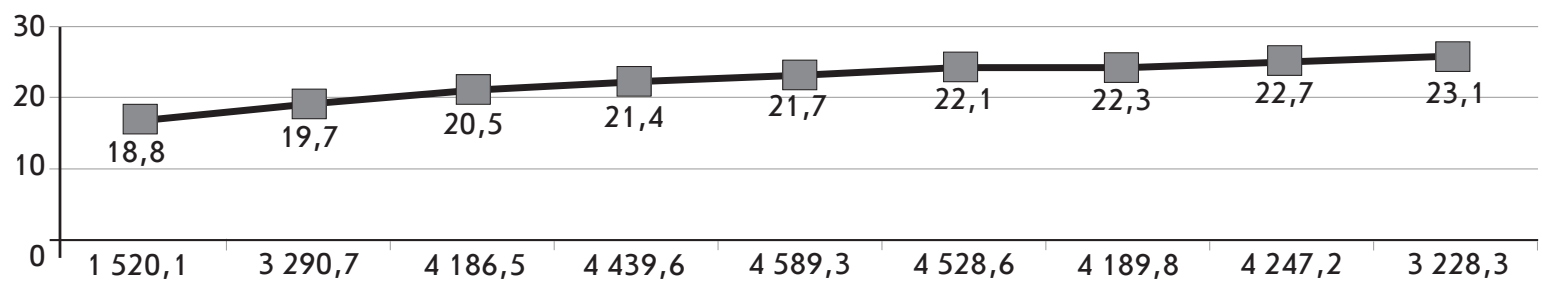

Рис. 3. Функция $\operatorname{Pr}=f(W o)$ 
уравнения $y=a x+b$, характеризующего исследуемые процессы. Вычисления искомых коэффрициентов рекомендуется провести путем использования нормальной системы уравнений метода наименьших квадратов, записанной в следующем виде [11, с. 159]:

$$
\left\{\begin{array}{c}
\sum_{i=1}^{n} y_{i} x_{i}=a \sum_{i=1}^{n} x_{i}^{2}+b \sum_{i=1}^{n} x_{i} \\
\sum_{i=1}^{n} y_{i}=a \sum_{i=1}^{n} x_{i}+b n
\end{array}\right\} .
$$

Используя выражение (1), получаем значения коэфффициентов для трех исследуемых функций: $\operatorname{Pr}=f(S), \operatorname{Pr}=f(E n)$ и $P r=f(W o) . C$ учетом полученных значений исследуемые ффункции примут следующий вид: $\operatorname{Pr}=1,42 E n-893,11 ; \operatorname{Pr}=0,61$ Wo - 2 355,90; $\operatorname{Pr}=2,31 S-120619,66$.

По логике научного исследования функция обеспеченности населения жилой площадью зависит от размера всего жилищного фонда, отнесенного к числу жителей региона. Размер площади жилищного фонда увеличивается за счет ввода новых жилых домов и уменьшается за счет оттока ветхого и аварийного фонда. Ситуацию, связанную с изменением демографии, предлагается учесть путем введения поправочного коэффициента, соответствующего значениям темпа прироста населения страны. Исходя из этого с учетом данных фракторов аналитическое выражение функции обеспеченности населения жилой площадью запишется в виде $\operatorname{Prf}_{\left(s, E n, W_{0}\right)}=2,31 S+1,42 E n-0,61 \mathrm{Wo}-$ - $119156,87$.

Полученная функция показывает аналитическую зависимость между обеспеченностью населения жилой площадью и динамикой ее аргументов, содержащих информацию о количестве вводимого и выбываемого жилья. Для детального описания динамики обеспеченности населения региона жилой площадью необходимо представить изменение данной функции $\Delta \mathrm{Pr} / \operatorname{Pr}$ через относительное изменение ее аргументов $\Delta x_{i} / x_{i}$ и коэфорициент частной эластичности $E x_{i}(f)$. Математическое выражение, описывающее относительное изменение обеспеченности населения жилой площадью, для двух аргументов запишется в следующем виде [11, с. 140]:

$$
\frac{\Delta P_{r}}{P_{r}} \approx E x_{i}(f) \frac{\Delta x_{1}}{x_{1}}+E x_{i}(f) \frac{\Delta x_{2}}{x_{2}} .
$$

С учетом того что коэфффициент частной эластичности функции $y=f\left(x_{1}, x_{2}, \ldots, x_{n}\right)$ по переменной $x_{i}$ в точке $x^{0}=\left(x_{1}^{0}, x_{1}^{0}, \ldots \ldots x_{n}^{0}\right)$ представляет собой частные производные функции по одному из ее аргументов, становится возможным оценить скорость изменения исследуемого показателя при условии изменения одной его компоненты. Таким образом, математическое выражение для определения коэффрициента частной эластичности функции $E x_{i}$ запишется в виде [12, с. 137]

$$
\begin{aligned}
E x_{i}=\mid x=x^{0}= & \frac{x_{i}}{y} \cdot \frac{d_{y}}{d x_{i}} \mid x=x_{0}=\frac{x_{i}^{0}}{f\left(x_{1}^{0}, x_{2}^{0}, \ldots \ldots x_{n}^{0}\right)} \times \\
& \times \frac{d f\left(x_{1}^{0}, x_{2}^{0}, \ldots \ldots x_{n}^{0}\right)}{d x_{i}} .
\end{aligned}
$$

В данном случае применительно к выражению (2) имеем

$$
\begin{gathered}
\frac{\Delta P_{r}}{P_{r}} \approx\left(\frac{E n}{2,31 S+1,42 E n-0,61 W o-} \cdot \frac{d P_{r}}{d E n}\right) \cdot \frac{\Delta E n}{E n}- \\
-\left(\frac{\begin{array}{c}
-119156,87 \\
2,31 S+1,42 E n-0,61 W o- \\
-119156,87
\end{array}}{2} \cdot \frac{d P_{r}}{d W_{0}}\right) \cdot \frac{\Delta W_{0}}{W_{0}} .
\end{gathered}
$$

Частные производные

$$
\frac{d f\left(x_{1}^{0}, x_{2}^{0}, \ldots \ldots x_{n}^{0}\right)}{d x_{i}}
$$

имеют следующие значения: $d P_{r} / d E n=1,42$; $d P_{r} / d W_{0}=-0,61$. С учетом проведенных вычислений фрункция $\Delta P_{r} / P_{r}$ примет вид

$$
\begin{aligned}
& \frac{\Delta P_{r}}{P_{r}} \approx\left(\frac{1,42 E n}{2,31 S+1,42 E n-0,61 W_{0}-119156,87} \cdot \frac{\Delta E n}{E n}\right)- \\
& -\left|\left(\frac{0,61 W_{0}}{2,31 S+1,42 E n-0,61 W_{0}-119156,87} \cdot \frac{\Delta W_{0}}{W_{0}}\right)\right| \cdot 100 \% .
\end{aligned}
$$

Здесь значения приращения аргументов функции $\operatorname{Pr}=f\left(S, E n, W_{0}\right) \frac{\Delta E n}{E n}, \frac{\Delta W_{0}}{W_{0}}$ рекомендуется определять следующим образом.

Значение показателя $\Delta E n$ вычисляется как разница между объемами введенного в строй жилья за последующий и предыдущий периоды: $\Delta E n=E n_{\text {посл }}-E n_{\text {пред }}$, где $E n_{\text {пред }}-$ предшествующий объем вводимого жилья, $м^{2} ; E n_{\text {посл }}$ - последующий объем вводимого жилья (планируемый).

Значение показателя $E n_{\text {посл }}$ определяется в соответствии с выражением $E n_{\text {посл }}=(\mathrm{V} \times$ $\left.\times K_{\text {расш }}\right)$, где $V$ - объем жилья, вычисляемый исходя из проведения математической классификации жилищного фонда; $K_{\text {расш }}$ коэфффициент расширения, показывающий требуемое приращение обеспеченности жилищным фондом $\sigma=\frac{P r_{\text {планируемый }}}{P r_{\text {фактический }}}$. Величина коэффрициента определяется выражением $K_{\text {расш }}=7,2 \cdot \sigma$. 
Окончательно приращение аргументов функции обеспеченности населения жилой площадью определяется выражением $\Delta E n / E n_{\text {посл }}$.

Непосредственно приращение аргумента, характеризующего изменение ветхого и аварийного фонда, исчисляется выражением $\Delta W_{0} / W_{0_{\text {лее }}}$, где $\Delta W_{0}$ определится $\Delta W_{0}=W_{0_{\text {посл }}}-W_{0_{\text {пред }}}, W_{0_{\text {пред }}}$ - исходный объем ветхого и аварийного фронда. Величину показателя $W_{0_{\text {посл }}}$ рекомендуется определять с использованием выражения

$$
W_{0_{\text {посл }}}=\frac{V}{\sigma},
$$

где $\sigma-\frac{\sigma_{\text {планируемый }}}{\sigma_{\text {фактический }}}-$ коэфрфициент, отражающий требуемую динамику ветхого и аварийного фонда; $V$ - объемы ветхого и аварийного фонда, определяемые с использованием метода математической классификации жилищного фонда [12].

Расчетные значения показателя обеспеченности населения жилой площадью в зависимости от динамики основных аргументов, характеризующих введение в эксплуатацию жилья и его выбытие по причине ветхости и аварийности, представлены в табл. 4.

\begin{tabular}{|c|c|c|}
\hline \multirow[t]{2}{*}{$\begin{array}{l}\text { При изменении } \\
\text { показателей }\end{array}$} & \multicolumn{2}{|c|}{$\begin{array}{c}\text { Величина показателя } \\
\text { обеспеченности } \\
\text { жильем изменится на }\end{array}$} \\
\hline & $\%$ & $M^{2}$ \\
\hline $\begin{array}{l}\text { Увеличении вводимого } \\
\text { жилья }(E n) \text { на } 664,4 \text { тыс. } \text { м }^{2} \\
\text { и снижении объема ветхого } \\
\text { и аварийного фонда на } \\
1247,2 \text { тыс. м² }\end{array}$ & 0,47 & 22,8 \\
\hline
\end{tabular}

Окончание табл. 4

\begin{tabular}{|c|c|c|}
\hline \multirow[t]{2}{*}{$\begin{array}{c}\text { При изменении } \\
\text { показателей }\end{array}$} & \multicolumn{2}{|c|}{$\begin{array}{c}\text { Величина показателя } \\
\text { обеспеченности } \\
\text { жильем изменится на }\end{array}$} \\
\hline & $\%$ & $\mathrm{M}^{2}$ \\
\hline $\begin{array}{l}\text { Увеличении вводимого жи- } \\
\text { лья (En) на } 1 \text { 164,4 тыс. м² } \\
\text { и снижении объема ветхого } \\
\text { и аварийного фонда на } \\
1747,2 \text { тыс. }{ }^{2}\end{array}$ & 1,34 & 23,0 \\
\hline $\begin{array}{l}\text { Увеличении вводимого жи- } \\
\text { лья (En) на } 11 \text { 197,04 тыс. }{ }^{2} \\
\text { и снижении объема ветхого } \\
\text { и аварийного фонда } \\
\text { на } 2123,60 \text { тыс. м² }\end{array}$ & 87,10 & 42,5 \\
\hline
\end{tabular}

Разработанная и предложенная модель в рамках «воспроизводственного подхода» отражает динамику обеспеченности населения жилой площадью в зависимости от изменения ее основных аргументов и направленна на выработку эфффективной стратегии по улучшению условий проживания в стране, что позволяет достичь качественного решения жилищной проблемы на макроэкономическом уровне. Применение методов диффреренцирования функции к решению проблемы обеспеченности населения жилой площадью делает разработанную модель универсальным инструментом, позволяющим доработать существующие механизмы планирования жилищной политики в части обоснования необходимых для воспроизводства объемов жилья. Использование модели позволяет оценить изменение обеспеченности населения жилой площадью в зависимости от приращения совокупного размера жилищного фонда, чтобы уравновесить возникающий спрос на жилую недвижимость с существующим предложением на рынке жилья в регионах. Внедрение разработанной модели на федеральном, региональном или местном уровнях позволит повысить эффективность решения жилищной проблемы в рамках воспроизводства жилья в России.

\section{СПИСОК ИСПОЛЬЗОВАННОЙ ЛИТЕРАТУРЫ}

1. Case Study of the Core Structure Succeeding Method for Tall Building Construction [Electronic resource] / Y. S. Choi [et al.] / / Journal of Construction Engineering and Management. - 2016. — Vol. 142, iss. 12. - Mode of access: http://ascelibrary.org/toc/jcemd4/142/12.

2. Droste C. Livability / C. Droste / / Housing Review. - 2015. - P. 57-74.

3. Светник Т. В. Корректировка стратегий строительства жилья в условиях кризиса / Т. В. Светник // Известия Иркутской государственной экономической академии. - 2015. - T. 25, № 6. - C. 941-946. - DOI: 10.17150/1993-3541.2015.25(6).941-946.

4. Understanding delays in housing construction: evidence from Northern Ireland / J. McCord [et al.] // Journal of Financial Management of Property and Construction. - 2015 - № 3. - P. 286-319.

5. Развитие российского общества: социально-экономические и правовые исследования / под ред. М. А. Винокурова, А. П. Киреенко, С. В. Чупрова. - М. : Наука, 2014. - 622 с.

6. Patacchini E. Residential choices of Young Americans / E. Patacchini, T. Arduini // Journal of Housing Economics. - 2016. - Vol. 34. - P. 69-81.

7. Ching F. D. K. Building Codes Illustrated: A Guide to Understanding the 2015 International Building Code / Francis D. K. Ching, S. R. Winkel. — New York : John Whiley and Sons Inc., 2016. - 448 p. 
8. Effects of recycled aggregates from construction and demolition wastes on mechanical and permeability properties of paving stone, kerb and concrete / F. Özalp [et al.] / / Construction and Building Materials. - 2016. Vol. 110, № 5. - P. 17-23.

9. Цвигун И. В. Развитие методологии управления качеством процессов в жилищной соере / И. В. Цвигун, С. А. Астафьев. - Иркутск : Изд-во БГУЭП, 2011. - 275 с.

10. Чернышов Л. Н. Капитальный ремонт многоквартирных домов: проблемы формирования и направления развития / Л.Н.Чернышов, С. А. Астафьев, В.П.Вакулина / / Известия Иркутской государственной экономической академии. - 2015. - T. 25, № 1. - C. 85-94. — DOI: 10.17150/1993-3541.2015.25(1).85-94.

11. Математика-1: программа курса, основные теоретические сведения, задачи / Р. З. Абдуллин [и др.]. - Иркутск : Изд-во БГУЭП, 2003. - 255 с.

12. Хомкалов Г. В. Классификация форм и источников финансирования работ при воспроизводстве жилья с различной степенью износа / Г.В.Хомкалов, И. Г. Торгашина, К. В. Демьянов / / Известия вузов. Инвестиции. Строительство. Недвижимость. - 2016. — № 2 (17). - С. 103-112.

\section{REFERENCES}

1. Choi Y. S., Lim I., Kim T., Cho H. Case Study of the Core Structure Succeeding Method for Tall Building Construction. Journal of Construction Engineering and Management, 2016, vol. 142, iss. 12. Available at: http:// ascelibrary.org/toc/jcemd4/142/12.

2. Droste C. Livability. Housing Review, 2015, pp. 57-74.

3. Svetnik T. V. Adjusting housing construction strategies under the housing crisis. Izvestiya Irkutskoi gosudarstvennoi ekonomicheskoi akademii = Izvestiya of Irkutsk State Economics Academy, 2015, vol. 30, no. 6, pp. 941-946. DOI: 10.17150/1993-3541.2015.25(6).941-946. (In Russian).

4. McCord J., McCord M., Davis P. T., Haran M., Rodgers W. J. Understanding delays in housing construction: evidence from Northern Ireland. Journal of Financial Management of Property and Construction, 2015, no. 3, pp. 286-319.

5. Vinokurov M. A., Kireenko A. P., Chuprov S. V. (eds.). Razvitie rossiiskogo obshchestva: sotsial'noekonomicheskie i pravovye issledovaniya [Russian society development: social-economic and legal research]. Moscow, Nauka Publ., 2014. 622 p.

6. Patacchini E., Arduini T. Residential choices of Young Americans. Journal of Housing Economics, 2016, vol. 34, pp. 69-81.

7. Ching Francis D. K., Winkel S. R. Building Codes Illustrated: A Guide to Understanding the 2015 International Building Code. New York, John Whiley and Sons Inc., 2016. 448 p.

8. Özalp F., Dilşad H., Mustafa K. Y., Kaya Ö., Şahin A. Effects of recycled aggregates from construction and demolition wastes on mechanical and permeability properties of paving stone, kerb and concrete. Construction and Building Materials, 2016, vol. 110, no. 5, pp. 17-23.

9. Tsvigun I. V., Astafev S. A. Razvitie metodologii upravleniya kachestvom protsessov v zhilishchnoi sfere [Developing methodology of the quality management in the sphere of housing construction]. Irkutsk, Baikal State University of Economics and Law Publ., 2011. 275 p.

10. Chernyshov L. N., Astafiyev S. A., Vakulina V. P. Apartment buildings capital repairs: funding problems and development trends. Izvestiya Irkutskoi gosudarstvennoi ekonomicheskoi akademii = Izvestiya of Irkutsk State Economics Academy, 2015, vol. 25, no. 1, pp. 85-94. DOl: 10.17150/1993-3541.2015.25(1).85-94. (In Russian).

11. Abdullin R. Z., Anapolsky L. Yu., Gorodkova A. R., Dykhta V. A., Kolokolnikova G. A. Matematika-1: programma kursa, osnovnye teoreticheskie svedeniya, zadachi [Math-1: course syllabus, theoretical basics, problems]. Irkutsk, Baikal State University of Economics and Law Publ., 2003. 255 p.

12. Khomkalov G. V., Torgashina I. G., Demyanov K. V. Classification of forms and sources of financing in the reproduction of residential constructions with different dilapidation levels. Izvestiya vuzov. Investitsii. Stroitel'stvo. Nedvizhimost ${ }^{\prime}=$ Proceedings of Universities. Investment. Construction. Real estate, 2016, no. 2 (17), pp. $103-112$. (In Russian).

\section{Информация об авторах}

Хомкалов Геннадий Владимирович - доктор экономических наук, профессор, кафедра экономики и управления инвестициями и недвижимостью, Байкальский государственный университет, 664003, г. Иркутск, ул. Ленина, 11, e-mail: hgv@isea.ru.

Торгашина Ирина Геннадьевна - кандидат экономических наук, доцент, кафедра экономики и управления инвестициями и недвижимостью, Байкальский государственный университет, 664003, г.Иркутск, ул. Ленина, 11, e-mail: hig06@mail.ru.

Демьянов Константин Васильевич - кандидат экономических наук, ООО «Росгосстрах», 677000 , Республика Саха (Якутия), г. Якутск, ул. Пушкина, 10, e-mail: sql1979@rambler.ru.

\section{Authors}

Gennady V. Khomkalov - DSc in Economics, Professor, Economics and Investment and Real Estate Management Department, Baikal State University, 11 Lenin St., 664003, Irkutsk, the Russian Federation, e-mail: hgv@isea.ru.

Irina G. Torgashina - PhD in Economics, Associate Professor, Economics and Investment and Real Estate Department, Baikal State University, 11 Lenin St., 664003, Irkutsk, the Russian Federation, e-mail: hig06@ mail.ru.

Konstantin V. Demyanov - PhD in Economics, manager, JSC «Rosgosstrakh», 10 Pushkin St., 677000, Republic of Sakha (Yakutia), Yakutsk, the Russian Federation, e-mail: sql1979@rambler.ru. 


\section{Для цитирования}

Хомкалов Г. В. Применение «воспроизводственного подхода» в целях решения жилищной проблемы в стране / Г. В. Хомкалов, И. Г. Торгашина, К. В. Демьянов / / Известия Байкальского государственного университета. - 2018. - Т. 28, № 1. - С. 63-73. DOI: $10.17150 / 2500-2759.2018 .28(1) .63-73$.

\section{For citation}

Khomkalov G. V., Torgashina I. G., Demyanov K. V. Application of the "Reproductive Approach» for the Purpose of Solving the Housing Problem in Russia. Izvestiya Baykal'skogo gosudarstvennogo universiteta $=$ Bulletin of Baikal State University, 2018, vol. 28 , no. 1, pp. 63-73. DOI: 10.17150/25002759.2018.28(1).63-73. (In Russian). 